\title{
The Effect of Feedback on Instructional Behaviours of Pre-service Teacher Education
}

\author{
Serkan Gürkan \\ English Language Department, Faculty of Education, Kocaeli University, 41380, Kocaeli, Turkey
}

Copyright@2018 by authors, all rights reserved. Authors agree that this article remains permanently open access under the terms of the Creative Commons Attribution License 4.0 International License

\begin{abstract}
Teacher training programs have a pivotal role in sophisticated Turkish education system. In order to reach high standards in teacher training, trainers should encourage and supervise pre-service teachers to use effective teaching skills and strategies. To ensure that providing feedback is regarded to be a widely accepted way for maximizing the use of teaching skills and strategies on newly established behaviours. With this in mind, the aim of this paper was to gain insights into the effects of immediate corrective feedback (delivered via a wireless FM listening system BIE) and delayed feedback on student teachers' instructional behaviours during instruction in teaching practicum. The research design is mixed-method sequential explanatory design. Thus, quantitative and qualitative researches were conducted respectively. Thirteen student teachers participated in the quantitative study and data was collected via a checklist. Out of thirteen student teachers, the semi-structured interviews were conducted with six student teachers for the qualitative phase. Immediate corrective feedback was found to be a more effective way than delayed feedback to help student teachers to be effective users of teaching practices such as class management, body language, voice level, use of intonation and stress, so forth. The findings were discussed and suggestions for further research were also addressed.
\end{abstract}

Keywords Feedback, Teacher Education, Pre-service Teachers

\section{Introduction}

Teacher training programs in all fields have crucial roles in training qualified prospective teachers for the education of future generations. With this in mind, training of a pre-service teacher is not easy as it is thought. It is highly complicated that it has many facets to be considered from loading students with theoretical knowledge to field experiences needed for meeting the theory with practice.
These experiences enable students reflect their own practices to the field and monitor their own progress with the help of hand on experiences. By this way students can find real opportunities to see where they are in terms of reaching their potentials in their professional careers. Field experiences like school practicum are regarded to be an indispensable part of teacher training programs [1-3]. On the other hand, many researchers believe that some branch teachers, like general and special education, did not feel they were receiving sufficient supervision consistently in their practicum experiences [4]. A pre-service teacher can perform quiet well in a practicum classroom but this might be due to the help of a more knowledgeable peer or the supervision offered by an elder person. This view is in line with Zone of Proximal Development concept which was put forward by the pioneer of Social Constructivist View, Vygotsky [5]. Supportively, it was demonstrated that teachers can positively adjust their teaching practices when they are provided constructive, systematic feedback on their teaching practices [6]. It is a widely accepted belief that one of the best alternatives for enhancing student learning is providing feedback to the students. Thus, students find a chance to keep themselves on track generating suggestions for development in fields where they may not perform well. Appropriate feedback may be helpful in understanding of a student on how s/he has been doing so far as well as noticing which areas of knowledge still required being pursued [7]. In an instructional setting, feedback is described as one of the many procedures that inform a student whether his/her response is right or wrong. Additionally, feedback can also provide instructional information to the student that gives a reason for why a response is correct or incorrect [8]. Therefore, giving feedback to student teachers is of crucial importance for their professional teacher development. By this way, student teachers can be aware of their strengths and weaknesses in their field experiences of teaching. Research findings revealed that any amount of feedback is better than no feedback condition, and there is a high correlation between the amount of information in feedback and the impact on student's comprehension and resulting 
performance [9, 10, 7].

There have been many studies on effect of feedback on learning so far. According to the literature, feedback is systematic, positive and corrective [11,12], immediate $[13,14]$. Based on the literature, it would be reasonable to assume that corrective and immediate feedback is applicable to teacher training field experiences.

Feedback is also classified in terms of when it is delivered. To enlighten, there are controversial views on which types of feedback is more effective. While one group of researchers argues that immediate feedback (instant feedback) is superior to delayed one, the opposing group believes that delayed feedback is more advantageous to learning. In a number of studies, it has been shown that immediate feedback is superior to delayed feedback in increasing desirable behaviors such as teaching how to deliver positive consequences and instructional prompts $[14,15]$. In a supporting study, the teacher's immediate scaffolding of inappropriate behaviour was more effective if some time was allowed to elapse in a classroom setting [16]. Another supportive view was made by advocates of operant learning theory indicating precise, immediate, frequent feedback increases efficacy and efficiency of learning in school aged students $[17,18]$. When feedback is delayed, it causes learners to practice errors, and when learners repeat errors, they may learn to perform skills incorrectly even leading to fossilization of errors [19].

So far the importance of providing feedback was discussed. Yet, giving it traditionally is not the only way. Alternatively, technology can be integrated into classrooms in giving feedback to students. For instance, proponents of former group have developed a procedure known as Immediate Feedback Assessment Technique (IFAT) $[20,21]$ which allows the provision of immediate feedback to a student on an item-by item. The study of Epstein, Lazarus, Calvano, Matthews, Hendel, Epstein and Brosvic [22], which seeks for the effect of computer based immediate feedback on students learning, suggests that the advantage of immediate feedback can be seen both in rapid verification of a learner's correct understanding of a concept and a rapid indication of where and when a misunderstanding occurs. Supportively, Lancioni and Boelens [23] demonstrated the efficacy of immediate computer-delivered feedback in increasing the drawing accuracy of children with mental retardation. However, Clarke [24] argues that there are no differences in student performance between computer and traditional paper-based programs, or the observed differences are not statistically significant [25].

Despite the observed effect of computer based immediate feedback, practicality of it remains questionable due to the fact that this procedure cannot be easily applied in many classes without using computer technology. On the contrary, proponents of delayed feedback argue that this type of feedback is more effective because of the Delayed Retention Effect (DRE), assuming that learners who have delayed feedback for some period of time recall significantly more than the subjects who received immediate feedback following a learning assessment activity [26,27]. According to these researchers, corrective feedback received immediately after an incorrect response blocks or interferes with learner's ability to comprehend and internalize the correct answer. Therefore learners should be given a chance to forget those incorrect responses firstly. Maintaining such a period of time or delay between learner's initial incorrect response and the feedback provided enables learners to replace correct response with the incorrect one. This event was first hypothesized and termed by Kulhavy and Anderson [28]. In the light of the discussion above, the question of which type of feedback is more effective remains unanswered.

As noted above, technology can be integrated into instructional settings for many reasons. As it is widely accepted, most supervisory feedback given to pre-service teachers in teacher training is delayed and it depends on use of field notes, checklists and anecdotal post teaching conference with feedback occurring after the teaching experience [1,29]. It is a high probability that this delay may decrease effectiveness of supervisor feedback. Thus, our attention in giving effective feedback turns to the immediate feedback. But applying immediate feedback in classroom without disruption is not an easy job. Unfortunately, it has several obstacles like disruption of on-going class activities. When immediate feedback is presented, other students likely observe the interaction between the teachers increasing the probability that other disruptions will occur thereby. This situation may potentially reinforce the students to misbehave at those moments [30].

Innovations in technology, however, enable supervisors to provide immediate corrective feedback without causing any disruption during the instruction period. One type of technological assistance is a mechanical third ear, known as "bug in the ear" (BIE), termed by Korner and Brown [31], which can be used to provide immediate feedback in diverse settings, from training psychometrics [32] to teaching interview skills to medical students [33]. In terms of teacher training, Giebelhaus [1], used BIE technology with pre-service teachers in providing specific prompts on 14 different behaviours when they are engaged in undesirable instructional behaviour during the lesson which was undesirable.

In the light of above literature, the aim of this study was to gain insights into the effects of immediate corrective feedback (delivered via a wireless FM listening system BIE) and delayed feedback on student teachers' instructional behaviours during instruction in teaching practicum. The following sub-questions guided the research process.

\section{Quantitative Research Questions}

1. Did the use of immediate feedback delivered wireless FM listening system BIE cause significant 
difference on student teachers' teaching performances?

2. Did the use of delayed feedback cause significant difference on student teachers' teaching performances?

3. Was there a significant difference between performances of student teachers who were given immediate feedback and delayed feedback?

\section{Qualitative Research Questions}

1. What are student teachers' perceptions about the benefits of immediate feedback delivered via wireless FM listening system BIE?

2. What are student teachers' perceptions about the benefits of delayed feedback?

\section{Methodology}

\subsection{Research Design}

The study is in mixed-method sequential explanatory design. The sequential explanatory research design aims to benefit from qualitative data to aid in explaining and interpreting the results of quantitative results [34]. In this study, the data was collected over the period of time in two successive stages. Thus, the quantitative data was collected and analysed first. Then, researcher collected qualitative data in the second phase to interpret quantitative results.

\subsection{Procedure of Delivering Feedbacks}

\subsubsection{Participant and Setting}

Thirteen pre-service teachers, 6 males and 7 females, participated in the study. They were all senior students sharing similar educational backgrounds and they were all 22 years old. The participants were all seniors at a state university in an English Language Department having their last terms at the program before graduation. The seniors were supposed to take School Practicum course compulsory course to be entitled as English Teachers. The participants were selected randomly from a student pool of 92 pre-service teachers. They were told that their performances would be observed and scored, they would be given feedback on their work in the light of the study.

As stated above the participants were 13 seniors in an E.L.T. department at a state university. During their training, pre-service teachers have experienced many micro-teaching applications in university classrooms. But they could not find necessary chances to see how they can apply their theoretical knowledge they have learned and transfer their knowledge into a real K-12 classroom atmosphere where they can monitor their own progress in collaboration and liaison of their peer pre-service teachers, their coordinator teachers at schools and their supervisors from their departments. The success and the progress of the pre-service teachers rely on the strong ties of this triad. Normally, the practicum lasts 14 weeks and the students are supposed to follow 5 hours training at the state school and 1 hour at their departments with their supervisors. Students spend their 4 hours at state schools by monitoring the coordinator teacher (his/her actions, behaviours, strategies and skills s/he use, how s/he corrects errors etc.) and 1 hour by performing a teaching experience where they can find the necessary opportunities to apply what they have learnt so far (both theoretical knowledge and microteaching practices). After each performance, they are required to fill some sort of forms and prepare plans which enable supervisor to check what is going on during each individual pre-service teacher's practicum. Supervisor examines the reports which are submitted weekly by the students and give delayed feedback to them in a scheduled hour at the department either in groups or individually. Naturally, it is a must for supervisors to plan ahead and visit the schools for the purpose of making good connections with coordinator teachers and monitor pre-service teachers' individual performances. It is highly crucial that supervisor should visit practicum schools regularly and make the students feel that they are under monitoring. Otherwise the role of the supervisors remain only as "passing clouds" [35] which symbolizes that the supervisor only visits practicum school rarely and he is nowhere to be seen when needed. More visits mean more monitoring which enables students to receive more feedback from their supervisors on their progress.

\subsubsection{Procedure}

As noted above, the study consists of three phases which lasted 8 weeks with three groups. All participants were told about the aims of the study and they were randomly assigned into two groups. In pre-observation phase both groups of pre-service teachers were told to follow their plans. They were required to go to practicum school, monitor and perform during fifteen scheduled hours in three weeks. The main aim of the time period is to make student teachers orient themselves to the practicum school environment with coordinator teachers and materials in classes as well as students. Their performances were not observed until the end of third week. Their weekly reports were collected but they were not examined and were not scored. After three weeks of orientation each individual pre-service teacher performed and the performances were observed. Performances were scored by the observers but neither of the groups received feedback. Beginning from the $4^{\text {th }}$ week, the second phase started. In coordination with the state school coordinator teacher, in the light of the curriculum and with the permission of school administration 2 pre-service teachers from the $1^{\text {st }}$ group were ready to perform. Before they perform, teachers were told and explained how the wireless FM listening system operates. The system was quiet handy and it can easily be 
found in big chain media store markets It consists of a transmitter and a headset worn by the supervisor, seated in the back corner of the class and a pocket receiver and earphone to hear the immediate feedback from the supervisor were used by pre-service teacher. For experimental reasons, immediate feedback was defined as feedback provided in one to three seconds just after the instructional behaviour was observed. The equipment was tiny and could easily be hidden that the system was not disruptive since it was not seen by the students in classroom. Before the intervention each teacher had at least one practice session using Bug in the Ear technology (BIE) to get used to it. During 15 minutes practice sessions, teachers received one or two word utterance feedback in accordance with the lesson content ("modal" to signal a model is needed in that context etc.). Feedbacks regarding class management, body language, voice level, use of intonation and stress etc. were not provided throughout these practice sessions in order not to affect the results of study. After training sessions six student teachers in the first group instructed the class during separate hours. During the instruction, supervisor provided immediate feedback to teachers hand on teaching experience (such as "time" for "you are running out of time" or "hurry up" when the teacher has time management problem, "body" for use your body language more effectively, "voice" for speak up or adjust your voice level, "tune" for intonation of a current linguistic item, and "stress" for be careful about giving the right stress of a current linguistic item). Immediate feedback was also heard by two separate observers sitting at the back of the class. Once the first performances finished, the pre-service teachers were thanked but no feedback was given to them. They were requested to prepare for the next performances. The same student teachers were provided immediate feedback during their separate performances in the next week with same classes. The procedure was same and it was also valid for this second session. At the same day with these student teachers' first performance, seven students in the $2^{\text {nd }}$ group had their first performances. But this time they were not given immediate corrective feedback via wireless FM transmitter. Each student teacher's hand on teaching experiences was observed by the same observers again and was scored with checklists. After they completed their session, the corresponding delayed feedbacks were provided individually at the department 3 days after their performances. These students performed once again next week with the same procedure and they were given a second delayed feedback individually at the department again on the criteria specified earlier. All the first performances were done at the same day in different hours.

After 15 days, the third phase of the study started and each pre-service teacher from each group instructed the same classes again. Including the intervention phase all participating teachers submitted their lesson plans related to their own performances. These plans as well as checklists made it easier for observers to evaluate what was planned and what was happening at that time. The post observations were scored as well as the pre-observations. The post-observations were believed to enable the researcher to notice the effect(s) of the intervention by comparing the pre-service teachers' behaviours and actions during their performances on diverse teacher behaviours such as class management, body language, voice level, use of intonation and stress etc. The summary of the procedure can be seen in Table 1 .

Table 1. Summary of Procedure

\begin{tabular}{|cccccc|}
\hline & 1st Phase Orientation Pre-observation & \multicolumn{2}{c|}{ 2nd Phase Intervention } & 3rd Phase Post-observation \\
\hline Time & 1st, 2nd, 3rd & 4th week & 5th week & 6th week & 8th week(15 days after the \\
intervention 40’
\end{tabular}




\subsection{Quantitative Phase}

\subsubsection{Data Collection}

The study seeks for understanding the effects of immediate corrective feedback and delayed feedback in school practicum of pre-service teachers and it is in the form of mixed-method sequential explanatory design. Therefore thirteen seniors were placed in two groups. The students in each group assigned randomly. Data collection started at the spring term of 2016-2017 academic years and it lasted eight weeks. Throughout the study pre-service teachers' teaching performances were observed. The first phase of sequential explanatory design has three steps; pre-observation, intervention and post-observation. In pre-observation phase, the pre-service teachers were not given any types of feedback, neither immediate nor delayed. In the intervention phase the 1st group got the treatment and pre-service teachers were given immediate corrective feedback via a wireless FM listening system (BIE) during their teaching performances, while the 2nd group of teachers was given only delayed feedback a few days later at scheduled time at the department. Finally, in the post-observation phase, performances of both groups of teachers were observed again.

Two lecturers from the same E.L.T. department, who also contributed to training as supervisor for different groups of pre-service teachers, independently collected data from the classroom observations by scoring students' performances through checklist (see Appendix). The checklist used for assessing teachers performances includes 20 items representing teaching behaviours. Each item is 5 points ( $20 \times 5=100 p t s)$. Next to each item there is a row enabling assessors to take notes and comment on it. For agreement sessions, checklists of two randomly selected pre-service teachers' performances were analysed. Training session for evaluation continued till two separate observers and supervisor reached $85 \%$ of agreement on the occurrence of corrected behaviour after receiving either immediate feedback or delayed feedback.

\subsubsection{Data Analysis}

Since the sample of the study includes 13 participants, nonparametric tests were used during data analysis. As Russell and Purcell [36], the non-parametric tests should be used with small sample sizes $(n<30)$, since the small sample sizes do not validate assumptions of normality. While Wilcoxon signed ranks test was used for the analyses of the first and second research questions, Mann-Whitney U test was benefited for the analysis of the third research question.

\subsection{Qualitative Phase}

\subsubsection{Data Collection and Analysis}

After the collection of quantitative data, semi-structured interviews were conducted with six participants, three of which from immediate feedback group and another three from delayed feedback group. In the analyses of the data content analysis was used. The interview questions were addressed to the participants in accordance with the groups they are in. The participants were requested to answer the following interview questions;

1. What do you think of immediate feedback delivered via wireless FM listening system BIE?/ What do you think of delayed feedback?

2. Did you find immediate feedback delivered via wireless FM listening system BIE useful? / Did you find delayed feedback useful?

3. Did immediate feedback / delayed feedback make any change in instructional behavior in your teaching experiences?

During the interviews, digital voice recording was used, and data were transcribed verbatim. In order to preserve the anonymity of participants, all personal identifiers were removed and they were given codes depending on the feedback they receive (e.g.: IST1: Immediate feedback, student teacher, 1; DST1: Delayed feedback, student teacher, 1).

\section{Findings}

\subsection{Quantitative Findings}

As noted above, in the baseline situation, three weeks period before the pre-observation, pre-service teachers were given considerable time to acclimate themselves to the instructional setting. Beginning from the fourth week pre-observation phase was completed. To recap, no forms feedback was delivered to any of the teachers at the pre-observation phase. Scores regarding the teaching performances of pre-service teachers, which were obtained through scoring of the observed teaching behaviours with checklist, are given below. Accordingly teachers in the first group scored higher than the other groups $(M=60,5)$. The second group of teachers got approximate scores to their previous counterparts with $(M=57,5)$. Based on the findings it can be inferred that there are not much difference in the performances of student teachers in baseline situation.

With the intervention phase, the first student teachers in the first group were delivered immediate corrective feedback through their performances. Checklists were used to keep track of the student teachers' progress. As the supervisor was delivering immediate feedback to the students, the observers were also listening to the prompts. After two weeks observers commented that the treatment went smoothly with no problem at all. The system transmitter and earphones were operating regularly and the immediate prompts were heard by the student teachers. Compared to the first phase, student teachers in the first group performed better with the help of instant corrections. 
They appeared to be more relaxed and confident than their previous performances. On the other hand the other student teachers who were delivered delayed feedback, also performed better. They seemed they were getting used to the stage. As noted earlier, delayed feedback sessions were held at a scheduled hour at the department and both the student teachers in the delayed feedback group and the observers were present at that post conference. The effects of immediate and delayed feedback sessions were seen at the two groups.

Finally, after the intervention, all student teachers were observed for the last time after 2 weeks of period time from the intervention. During this period none of the groups were delivered any feedback. Their performances were rated and the mean differences between the groups are presented below as well as comments on behaviour differences in each group of teachers.

The post-observation session revealed that the group who received immediate feedback via wireless FM listening system performed highly better than the other groups. (M=77). This finding indicates a 16.5 point increase between the pre and post observations, emphasizing that immediate feedback was found to be helpful and fruitful during the instruction period. Although there was 9,5 point increase in the score of the group who received delayed feedback $(M=67)$, this was not high as it was in immediate feedback group.

After descriptive analysis, the researcher conducted Wilcoxon signed rank tests to understand whether the use of immediate feedback delivered wireless FM listening system BIE caused significant difference on student teachers' teaching performances (Table 2).

The results shows that the use of immediate feedback cause significant difference on student teachers' performances $(Z=-2,207 ; p=0,027<0,05)$.

After analysing the effect of immediate feedback, the Wilcoxon signed ranks test was applied to understand whether delayed feedback caused significant difference on student teachers' teaching performances (Table 3).

The results on Table 3 indicates that the use of delayed feedback cause significant difference on student teachers' performances $(Z=-2,371 ; p=0,018<0,05)$.

After analysing the effect of immediate and delayed feedback, the Mann Whitney U test was applied to examine whether there is a significant difference between performances of student teachers who were given immediate feedback and delayed feedback (Table 4).

The results of Mann Whitney $U$ test indicates that there is a significant difference between performances of student teachers who were given immediate feedback and delayed feedback $(U=-2,73 ; p=0,01<0,05)$.

Based on the findings, it would not be wrong to assume that, regardless of the type, any form of feedback, whether immediate or delayed, affected the performances of the pre-service teachers positively in school practicum. However, the effect of immediate feedback was more apparent in that when the feedback was presented immediately after the incorrect teaching behaviour, it aided teachers more than delayed feedback in correcting the undesirable instructional behaviour. This does not mean that delayed feedback is useless. When the mean differences in the second group were observed, it was seen that delayed feedback supplemented teachers in correcting their instructional behaviours but the effect was not as powerful as it was in immediate feedback sessions.

Table 2. Wilcoxon signed ranks test results for pretest and posttest scores of student teachers who received immediate feedback

\begin{tabular}{ccccccc}
\hline & & $\mathrm{N}$ & Mean Rank & Sum of Ranks & $\mathrm{Z}^{*}$ & $\mathrm{p}$ \\
\hline Immediate & Negative ranks & 0 &, 00 &, 00 & $-2,207$ & 0,027 \\
feedback & Positive ranks & 6 & 3,50 & 21,00 & \\
& Ties & 0 & & & \\
\hline
\end{tabular}

*based on negative ranks

Table 3. Wilcoxon signed ranks test results for pretest and posttest scores of student teachers who received delayed feedback

\begin{tabular}{ccccccc}
\hline & & $N$ & Mean Rank & Sum of Ranks & $Z^{*}$ & p \\
\hline Delayed & Negative ranks & 0 &, 00 & &, 00 & $-2,371$ \\
Feedback & Positive ranks & 7 & 4,00 & 28,00 & 0,018 \\
& Ties & 0 & & & \\
\hline
\end{tabular}

*based on negative ranks

Table 4. The results of descriptive analysis and Mann Whitney $U$ test results according to feedback type

\begin{tabular}{cccccccc}
\hline Groups & $\mathrm{N}$ & & $\mathrm{Sd}$ & Mean Rank & Sum of Ranks & $\mathrm{U}$ & $\mathrm{p}$ \\
\hline Immediate feedback & 6 & 4,60 & 0,114 & 10,17 & 61,00 & \\
Delayed feedback & 7 & 4,02 & 0,345 & 4,29 & 30,00 & 0,01 \\
\hline
\end{tabular}




\subsection{Qualitative Findings}

The content analysis of data obtained from semi-structured interviews revealed two themes: Feedback for motivating and fastening the seatbelts. The themes will be explained in detail.

\subsubsection{Feedback for Motivating}

The student teachers stated that feedbacks they received were motivating for them since they helped them during their teaching practices. It was worth to mention that student from both groups thought in the same way. Some of the utterances from student teachers are presented below.

"My supervisor did not interrupt me anytime and delivered feedback on what I did right or wrong later on at the department in an elaborative manner. This aided me a lot. Because I found a chance to see why it was wrong and how I can correct my behavior." (DST2)

"And I can say that, all of this process motivated me for my next practices." (IST3)

"When I got my BIE during the lesson, I feel motivated. Because I knew that even I forgot what to do, I knew that my supervisor would direct me at that time." (IST1)

"I really felt myself more comfortable and confident in acting during the instruction. At first the existence of the supervisors affected me negatively. I felt that I could not do it but as minutes passed by, I got used to it, and realized that the fact that they will not interrupt me but gave feedback on my errors would help me for the next lessons, which was motivating." (DST3)

Some student teachers said they would prefer all types of feedback together. They commented that it would be more beneficial and motivating for them if they could receive.

"It was great for me to receive delayed feedback from my supervisor, but I would like to receive immediate feedback, as well. I forgot to correct some of the actions I received feedback after the practice. I believe that if I got delayed feedback for one course and immediate feedback for next course, it would be more helpful" (DST1)

"I think that I would have been more successful if I had received a combination of the feedback sessions. (DST2)

"However, I think that immediate feedback should also be complemented by delayed feedback since immediate feedback is short and it is not elaborate."(IST2)

\subsubsection{Fastening the Seatbelts}

The student teachers emphasized that both immediate and delayed feedbacks made them feel them safe, since they knew that if they made any mistakes their supervisors warned them and this process enabled them to improve their performances. Student teachers who received immediate feedback reported that;
"I really felt myself comfortable like I fastened my seat-belt. I felt like whatever I do my supervisor will guide me and give right directions if had a difficulty." (IST2)

"When I received the immediate prompts instantly, I hesitated what to do at first, I felt like everyone was hearing those prompts. But afterwards I got used to it and now I think when the feedback is presented immediately, you have a chance to fix what you did wrong on that second." (IST1)

"Feedback I got facilitated my flow of instruction, it scaffolded me that I felt I never go down. Thus it contributed me in doing the right thing at the right time."(IST5)

Student teachers who received delayed feedback similarly found the process helpful and safe.

"When the class was over and I received my feedback from my supervisor I feel, how can I put it, relieved let's say. Because he was there for me to show me the way and save me." (DST1)

"To be honest, the feedback I received helped me a lot. At least you are aware of what is wrong or right." (DST2)

As it can be seen from the utterances, it can be said that feedbacks they receive were beneficial and life saving for them. However one of the students mentioned some of the feedback did not contribute to him much.

"However, I should also note that I forgot some of the actions I did during the instruction, so I felt that some of the feedback they gave did not contribute me much." (DST3)

This might be due to lack of concentration or time period between the instructional behaviors acted and feedback given regarding those behaviours.

\section{Discussion}

It is impossible to deny that feedback is a powerful component of supervision in teacher training programs. Therefore the effect of it on pre-service teachers' progress cannot be ignored. Moreover, there have been studies in teacher training field that technological developments made it easier for supervisor to deliver immediate feedback without blocking the flow of instruction or disrupting the learners in class. To reiterate, the focus of this descriptive study was to gain insights into the effects of immediate corrective feedback (delivered via a wireless FM listening system BIE) and delayed feedback on student teachers' instructional behaviours during instruction in teaching practicum. The findings of the study revealed that both types of feedback were found to be effective. The findings also emphasize that immediate corrective feedback was more effective and it contributed to the progress of pre-service teachers. Besides, the observations and 
interviews made it obvious that the use of system is not disruptive. Based on the findings, one can conclude that any form of feedback might not be sufficient enough by itself. Therefore, supervisors are recommended to use a mixture of feedback types according to the needs of pre-service teachers.

Literature shows that there have been many studies on the effects of immediate and delayed supervisor feedback on teacher instructional behaviour. The findings of this study are in accordance with the following studies examining the effect of immediate feedback on teacher use of appropriate prompts and positive consequences [15,14]. Supportively, the findings of this study supported the literature indicating immediate feedback is more effective in decreasing inappropriate behavior than delayed feedback $[37,38,14,39]$. In another study by Giebelhaus [1], in which wireless FM listening system was used in delivering feedback, the experimental group scored higher on measures of instructional behaviour than comparisons but only one of the 14 discrete skills targeted for change improved at a statistically significant level. This literature also supports the findings of this study that, although there were 20 different targeted behaviours, some of them could not be changed. This might stem from psychological aspects that students know that they are being tested, which is also referred as Hawthorne effect.

On the other hand, normally, as it was in this study, delayed feedback occurs 3 days after the observation as it was in O'Reilly et al. [14]. It might also be given immediately after the teaching session or at least in the same day [13]. What is common in all three studies is that immediate feedback was found to be faster in acquisition of effective teaching behaviours and greater overall accuracy in the use of those behaviours when compared to delayed feedback. The findings of this study are also in line with these studies but, additionally, I think that a combination of those types of feedback would contribute better in acquisition of certain teaching behaviours in teaching experiences of pre-service teachers.

\subsection{Limitations and Suggestions for Further Research}

Firstly, the study includes only thirteen seniors at an E.L.T. department of a state university. Therefore, the transferability of the results is questionable. A following potential study may include more pre-service teachers from in the sample yielding more generalizable results and/or more pre-service teachers from various departments for comparing the cross-departmental effects of independent variables.

Secondly, the intervention phase only includes three groups as; the group who received immediate feedback, the group who received delayed feedback and the group who received no feedback. An additional group of teachers who would receive both immediate and delayed feedback might be added to the design in order to analyse combined effects of both types of feedback on the targeted behaviours.

Thirdly, since one of the groups received no feedback, the participating teacher may have behaved, as they had been supposed to behave. In other words Hawthorne Effect might constitute a threat for the construct validity [40].

Fourthly, the construct validity might have also been under threat by evaluation apprehension. In this threat the participating students know that they are being tested. Thus, they might have deviated the results because of a desire to be evaluated favourably by the researcher [40].

Another limitation is that the study lasted 8 weeks. In such descriptive studies more time, prolonged engagement and persistent observation might be needed. The orientation period of the teachers was not observed in this study. A further study may include the missing parts of this study to reach more reliable and generalizable results.

Another suggestion for further research is that, stimulated recall protocol might be used to examine psychological aspects of teachers' choice of instructional behaviours during teaching practicum. To ensure this, recorded videos might be used in interviews with the pre-service teachers to figure out what made them choose a specific instructional behaviour. 


\section{Appendix: Class Instruction Feedback Form}

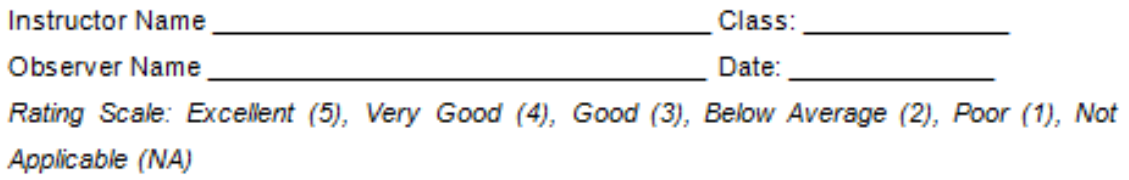

\begin{tabular}{|l|l|l|l|}
\hline & Criterion & Rating & Comments \\
\hline 1 & Instructor confidence level & & \\
\hline 2 & Control of class & & \\
\hline 3 & Enthusiasm & & \\
\hline 4 & Overall instructional activities & & \\
\hline 5 & $\begin{array}{l}\text { Match between objectives and } \\
\text { Activities }\end{array}$ & & \\
\hline 6 & Variety of activities & & \\
\hline 7 & Student involvement & & \\
\hline 8 & Overall communication skills & & \\
\hline 9 & Speaking clarity & & \\
\hline 10 & Eye contact with students & & \\
\hline 11 & Use of board and/or AV aids & & \\
\hline 12 & Asking questions & & \\
\hline 13 & Responding to student questions & & \\
\hline 14 & Mix of teacher talk and student talk & & \\
\hline 15 & $\begin{array}{l}\text { Attempts to link new material } \\
\text { with previous knowledge }\end{array}$ & & \\
\hline 16 & Use of examples & & \\
\hline 17 & Overall organization of class & & \\
\hline 18 & Opening & & \\
\hline 19 & Review & & \\
\hline 20 & Clarity of instructional objectives & & \\
\hline & TOTAL & & \\
\hline
\end{tabular}

[4] Buck, G., Morsink, C., Griffin, C., Hines, T., \& Lenk, L. (1992). Preservice training: The role of fieldbased experience in the preparation of effective special educators. Teacher Education and Special Education, 15, 108-123.

\section{REFERENCES}

[1] Giebelhaus, C. R. (1994). The mechanical third ear device: A student teaching supervision alternative. Journal of Teacher Education, 45, 365-373.

[2] Lignugaris-Kraft, B., \& Marchand-Martella, N. (1993). Evaluation of preservice teachers' interactive teaching skills in a direct instruction practicum using student teachers as supervisors. Teacher Education and Special Education, 16, 309-318.

[3] Warger, C. L., \& Aldinger, L. E. (1984). Improving student teacher supervision. The preservice consultation model. Teacher Education and Special Education, 7, 55-163.

[5] Chaiklin, S. (2003). "The Zone of Proximal Development in Vygotsky's analysis of learning and instruction." In Kozulin, A., Gindis, B., Ageyev, V. \& Miller, S. (Eds.) Vygotsky's educational theory and practice in cultural context. 39-64. Cambridge: Cambridge University.

[6] Greenwood, C. R., \& Maheady, L. (1997). Measurable change in student performance: Forgotten standard in teacher preparation? Teacher Education and Special Education, 20, 265-275.

[7] Lemley, D., C.,(2005). Delayed versus immediate feedback in an independent study high school setting. PhD dissertation submitted to Brigham Young University. 
[8] Mory, E. H. (1992). The use of informational feedback in instruction - Implications for future research. Educational Technology Research and Development, 40(3), 5-20.

[9] Cyboran, V. (1995). Designing feedback for computer-based training. Performance and Instruction, 34, 18-23.

[10] Olina, Z. \& Sullivan, H. J. (2002). Effects of classroom evaluation strategies on student achievement and attitudes. Educational Technology Research \& Development, 50(3), 61-75.

[11] Cossairt, A., Hall, V., \& Hopkins, B. L. (1973). The effects of experimenter's instructions, feedback, and praise on teacher praise and student attending behavior. Journal of Applied Behavior Analysis, 6, 89-100.

[12] Hao, R. (1991). The effects of corrective and non-corrective feedback on changing undesirable verbal teaching behavior. Doctoral dissertation, Southern Illinois University.

[13] Coulter, G. A., \& Grossen, B. (1997). The effectiveness of in-class instructive feedback versus afterclass instructive feedback for teachers learning direct instruction teaching behaviors. Effective School Practices, 16, 21-35.

[14] O’Reilly, M. F., Renzaglia, A., \& Lee, S. (1994). An analysis of acquisition, generalization and maintenance of systematic instruction competencies by preservice teachers using behavioral supervision techniques. Education and Training in Mental Retardation and Developmental Disabilities, 29, 22-33.

[15] O’Reilly, M. F., Renzaglia, A., Hutchins, M., Koterba-Bass, L., Clayton, M., Halle, J. W., \& Izen, C. (1992). Teaching systematic instruction competencies to special education student teachers: An applied behavioral supervision model. Journal of the Association for Persons with Severe Handicaps, 17, 104-111.

[16] Abramowitz, A. J., \& O'Leary, S. F. (1990). Effectiveness of delayed punishment in an applied setting. Behavior Therapy, 21, 231-239.

[17] Van Houten, R. (1980). Learning through feedback. New York, NY: Human Sciences Press, Inc.

[18] Wallace, G., \& Kauffman, J. (1973). Teaching children with behavior problems. Columbus, Ohio: Charles E. Merrill.

[19] Heward, W. (1997). Four validated instructional strategies. Behavior and Social Issues, 7, 43-48.

[20] Azevedo, R., \& Bernard, R. M. (1995). A meta-analysis of the effects of feedback in computer-based instruction. Journal of Educational Computing Research, 13, 111-127.

[21] Bugbee, A. C. (1996). The equivalence of paper-and-pencil and computer-based testing. Journal of Research on Computing in Education, 28, 282-299.

[22] Epstein, M. L., Lazarus, A. D., Calvano, T. B., Matthews, K. A., Hendel, R. A., Epstein, B. B., \& Brosvic, G. M. (2002). Immediate feedback assessment technique promotes learning and corrects inaccurate first responses. Psychological Record, 52, 187-201.

[23] Lancioni, C. E., \& Boelens, H. (1996). Teaching students with mental retardation and other disabilities to make simple drawings through a computer system and special cards. Perceptual and Motor Skills. 83, 401-402.

[24] Clarke, D. E. (2000). Evaluation of a networked self-testing program. Psychological Reports, 86, 127-128.

[25] Stephens, D. (2001). Use of computer-assisted assessment: Benefits to students and staff. Education for Information, 19, 265-275.

[26] Schroth, M. L. \& Lund, E. (1993). Role of delay of feedback on subsequent pattern recognition transfer tasks. Contemporary Educational Psychology, 18, 15-22.

[27] Swindell, L. K. \& Walls, W. F. (1993). Response confidence and the delay retention effect. Contemporary Educational Psychology, 18, 363-375.

[28] Kulhavy, R. W. \& Anderson, R. C. (1972). Delay-retention effect with multiple-choice tests. Journal of Educational Psychology, 63, 500-512.

[29] Sharpe, T., Lounsbery, M., \& Bahls, V. (1997). Description and effects of sequential behavior practicein teacher education. Research Quarterly for Exercise and Sports, 68, 222-232.

[30] Smith, T. E C., Polloway, E. A., Patton, J. R., \& Dowdy, C. A. (1998) Teaching students with special needs in inclusive settings. Needham Heights, MA: Allyn \& Bacon.

[31] Korner, I. N., \& Brown, W. H. (1952). The mechanical third ear. Journal of Consulting Psychology, 16, 81-84.

[32] Baum, D. (1976). An application of the "bug-in-the ear" communication system for training psychometrists. Counselor Education and Supervision, 15, 309-310.

[33] Hunt, D. D. (1980). "Bug-in-the-ear” technique for teaching interviewing skills. Journal of Medical Education, 11, 964 966.

[34] Cresswell, J. W., \& Plano Clark, V. L. (2011). Designing and conducting mixed methods research (2nd ed.). Thousand Oaks, CA: Sage Publications.

[35] Roberts, J. (1998). Language Teacher Education. London: Arnold.

[36] Russell, B. ve Purcell, J. (2009). Online research essentials: Designing and implementing research studies. United States of America: Jossey-Bass, A Wiley Imprint

[37] Jenson, W.J., Sloane, H.N., \& Young, K.R. (1988). Applied behavior analysis in education. Englewood Cliffs, NJ: Prentice Hall.

[38] Miltenberger, R.G. (1997). Behavior modification principles and procedures. Pacific Grove, CA Brooks/Cole Publishing Company.

[39] Sulzer-Azaroff, B., \& Mayer, G. R. (1991). Behavior analysis for lasting change, Fort Worth, TX: Holt, Rinehart and Winston.

[40] Lynch, B. K. (1996). Language program evaluation: Theory and practice. Cambridge: Cambridge University Press. 